\title{
ESTE LABIRINTO, 0 NOSSO AMULETO: CONSIDERAÇÕES SOBRE JULIO CORTÁZAR E ROBERTO BOLAÑO
}

This labyrinth, our amulet:

considerations about Julio

Cortázar and Roberto Bolaño

$r$ e i s

t a d e I

Francielly Baliana

i t e r a USP

t $\quad \mathbf{u} \quad \mathbf{r}$ a

o u $\mathbf{r}$ a

t $\mathbf{a}$ ve

s s i a 


\section{Resumo}

O conceito de labirinto é caro à literatura de Julio Cortázar, especialmente em obras como Rayuela e em contos como os reunidos em Bestiario. Como seu leitor, Roberto Bolaño por ora parece manifestar em obras como Amuleto a ressignificação dessa capacidade labiríntica, levando a literatura a outros patamares, nos quais as noções de construção e de destruição da narrativa podem ser associadas tanto à fatalidade de um abismo, quanto a um performativo que envolve o ponto de vista de quem narra. Este artigo tem por objetivo analisar como essas movimentações se dão em ambos os autores e em que medida aproximações e distanciamentos são possíveis dentro desse labirinto maior em que ambos convivem, a literatura latino-americana.

Palavras-chave: Julio Cortazar; Roberto Bolaño; Labirinto; Abismo; Performance

\section{Abstract}

The concept of labyrinth is important to Julio Cortázar's literature, especially in works like Rayuela and in tales like those gathered in Bestiario. As his reader, Roberto Bolaño for the time being seems to manifest in works like Amuleto the resignification of this labyrinthine capacity, taking literature to other levels, in which the notions of construction and destruction of the narrative can be associated with both the fatality of an abyss and the performance that involves the point of view of the narrator. This article aims to analyze how these movements occur in both authors and to what extent approximations and distances are possible within this larger labyrinth in which they both live together, Latin American literature.

Keywords: Julio Cortazar; Roberto Bolaño; Labyrinth; Abyss; Performance 


\section{Introdução}

A apresentação de Roberto Bolaño como um autor que essencialmente também é um voraz leitor já coloca o escritor chileno na sala que comporta alguns dos grandes escritores da literatura mundial. Assim como Jorge Luis Borges, Bolaño não se distancia de sua biblioteca de leituras quando empreende seus escritos, a começar pela poesia, com a qual iniciou seu caminho no campo literário, e da qual nunca se afastou tematicamente, uma vez que o cerco dos poetas, da vida dos poetas, de como escrever um bom poema perpassam boa parte de suas obras em prosa, que ganharam cena enquanto ensaios, contos e também romances. Deparar-se, portanto, com a escrita de Bolaño não raro é um deparar-se também com a escrita de outros autores que se manifestam das mais variadas maneiras, temáticas e formais, e cujas aparições, longe de fortuitas, soam como homenagens empreendidas pelo escritor àqueles que contribuíram para a formação do que se pode chamar seu cânone particular.

Dentre as relações tecidas com esses nomes, tais como Tchekhov, Borges, Kafka, Poe e Parra, um olhar para a íntima construção realizada à esteira de Julio Cortázar ganha destaque à medida em que esbarra tanto em questões temáticas quanto em escolhas formais. No caso do argentino, a particularidade surge ao se pontuar, principalmente, o mergulho realizado por Bolaño no que se pode conceber como o labirinto cortazariano. Em Rayuela, de 1963, e nos contos reunidos em Bestiario, de 1951, Cortázar esboça possibilidades de aparente imprevisibilidade para seus personagens que tanto caminham por cidades labirítincas, propiciatórias da possibilidade do encontro mas também da busca interminável, quanto convivem com o mistério e o enigma. Da mesma maneira, em Los Detectives salvajes, de 1998, Bolaño utiliza-se da formatação desse labirinto para tecer seus próprios encontros. O labirinto tornase o espaço em que personagens, entre os quais Arturo Belano e Ulisses Lima, vão de bar em bar, de café em café, de bairro em bairro, traçando uma rota inapreensível, mas especialmente caracterizada pela busca - seja ela pela poesia perfeita, seja ela por uma poeta desaparecida. Neste artigo, serão feitos breves apontamentos sobre alguns desses movimentos, especialmente a respeito das concepções de labirinto, do abismo, do estranhamento e da performance que perpassam ora a narrativa de Bolaño, ora a de Cortázar. Interessa verificar em que medida esses conceitos abrem espaço para uma aproximação possível entre ambos os autores.

\section{Entre todos os outros: um outro}

Em Rayuela, é possível analisar a formatação de um labirinto tanto temático quanto formal quando Cortázar permite, adverte e endossa que a leitura seja feita a 
partir de escolhas. A princípio, alerta o autor, o livro na verdade é formado por no mínimo dois livros, um "del lado de allá" e outro "del lado de acá”, organizados numa ordenação diferenciada de alguns dos 155 capítulos que compõem o todo, deixando alguns deles de fora, o que possibilita uma compreensão geográfica e não cronológica das relações entre os personagens, especialmente entre os protagonistas Horácio Oliveira e Maga.

Ao permitir a escolha de um capítulo em detrimento de outro, antes ou depois de outro, não é difícil observar o quanto essa possibilidade de optar pelo trilhar da história já carrega a experiência de labirinto. No entanto, para além de um circuito fechado em que as escolhas se limitam a um modelo prévio de caminho, o labirinto cortazariano assemelha-se à compreensão de rizoma apresentada por Gilles Deleuze e Félix Guattari (2010), segundo a qual cada ponto é capaz de conectar-se a todos os restantes e essa sucessão de conexões pode se estender ao infinito, visto que não há exterior ou interior nessa espécie de sistema. Para os críticos franceses, um rizoma é como um modelo descritivo ou epistemológico em que a organização dos elementos não percorre linhas de subordinação ou hierarquias, com uma base ou raiz dando origem a múltiplas ramas, mas se formando a partir da possibilidade de que qualquer elemento afete ou incida em qualquer outro.

Em Rayuela, essa ramificação se estende ao caminho percorrido pelos personagens. Horácio Oliveira, que inicia sua saga se perguntando se ¿Encontraría a la Maga?, percorre a plasticidade de Paris, a qual se movimenta de acordo com seus desencontros, e que é vista por ele, no capítulo 93, em um meta-diálogo, como "un centro, entendés, un mandala que hay que recorrer sin dialéctica, un laberinto donde las fórmulas pragmáticas no sirven más que para perderse. Entonces un cogito que sea como respirar París, entrar en él dejándolo entrar, neuma y no logos"1.

Percorrer o labirinto parisiense sem dialética, sem o pragmatismo das fórmulas, seria como se eximir de uma previsibilidade histórica já configurada. Adentrar, então, o labirinto de Cortázar é não necessitar mais da contraposição antitética que qualquer escolha parece predispor. "Ser ou não ser" deixa, portanto, de ser a questão. "Ser e não ser" passa habitar o espaço da existência, a celebrar a coexistência na qual o que é familiar, o que é estranho, o que é realidade e o que é devaneio tornam-se elementos que, juntos, compõem a ordem e a desordem que habitam qualquer opção possível ${ }^{2}$.

1 CORTÁZAR, Julio. Rayuela, 1995, p. 249.

2 O capítulo 110 de Rayuela é um trecho de Winter of Artifice, de Anaïs Nin, que expressa a inexistência de limites formais, de começo e de fim, na composição de um sonho, e demonstra a similaridade da forma onírica com a vida e a existência interminável presente ao longo de todo o restante do romance: "El sueño estaba compuesto como una torre formada por capas sin fin que se alzaran y se perdieran 
Os encontros aparentemente inapreensíveis entre Horácio e Maga ilustram a metáfora que pode ser atribuída à personagem, uma mulher uruguaia radicada na França, que também é mãe de um bebê de nome excêntrico, o bebê Rocamadour, e que à diferença de todo o círculo letrado de Horácio não se detém ou aparentemente não se preocupa com a racionalização constante da busca. Isso resulta propriamente na fatalidade que surpreende e deixa absorto aquele que empreende o percorrer do labirinto com a expressividade quase calculista de Horácio. A crítica à razão não poderia ser menos enfática:

\begin{abstract}
De acuerdo en que en ese terreno no lo estarían nunca, se citaban por ahí y casi siempre se encontraban. Los encuentros eran a veces tan increíbles que Oliveira se planteaba una vez más el problema de las probabilidades y le daba vuelta por todos lados, desconfiadamente. No podía ser que la Maga decidiera doblar en esa esquina de la rue de Vaugirard exactamente en el momento en que él, cinco cuadras más abajo, renunciaba a subir por la rue de Buci y se orientaba hacia la rue Monsieur le Prince sin razón alguna, dejándose llevar hasta distinguirla de golpe, parada delante de una vidriera, absorta en la contemplación de un mono embalsamado. Sentados en un café reconstruían minuciosamente los itinerarios, los bruscos cambios, procurando explicarlos telepáticamente, fracasando siempre, y sin embargo se habían encontrado en pleno laberinto de calles, casi siempre acababan por encontrarse y se reían como locos, seguros de un poder que los enriquecía. A Oliveira lo fascinaban las sinrazones de la Maga, su tranquilo desprecio por los cálculos más elementales. Lo que para él había sido análisis de probabilidades, elección o simplemente confianza en la rabdomancia ambulatoria, se volvía para ella simple fatalidad. «¿ Y si no me hubieras encontrado?», le preguntaba. «No sé, ya ves que estás aquí...» Inexplicablemente la respuesta invalidaba la pregunta, mostraba sus adocenados resortes lógicos ${ }^{3}$.
\end{abstract}

Todo esse aspecto de movimentação e de imprevisibilidade já era nutrido por Cortázar nos contos de Bestiario, que também leva esse percorrer do labirinto ao que se pode compreender como entrecruzamento com espécies de abismos. É possível observar que, em boa parte das histórias, o desfecho ou as motivações dos personagens permanecem indefinidos. O enigma ocupa posição central na coletânea, o que leva o leitor a questionar-se, por exemplo, sobre por que os personagens de

en el infinito, o bajaran en círculos perdiéndose en las entrañas de la tierra. Cuando me arrastró en sus ondas la espiral comenzó, y esa espiral era un laberinto. No había ni techo ni fondo, ni paredes ni regreso. Pero había temas que se repetían con exactitud”. (NÏN apud CORTÁZAR. Rayuela, 1995, p. 278). Aqui, a forma do labirinto e a forma da própria narrativa demonstram-se como a maior das relevâncias em detrimento dos próprios temas e conteúdos. Seria, portanto, na forma que se daria a expressividade diferencial de cada narrativa.

3 Ibidem, p. 21. 
"Casa Tomada" simplesmente abandonam sua casa, tomada por algo que não é revelado. Pergunta e resposta para esse mistério são pouco importantes, tendo em vista a maneira como esse abandono ocorre, assim como a temática não está em Cortázar - tal como em Bolaño - para competir com a forma. Esses vazios inferidos esboçam uma espécie de lugar daquilo que é impossível de se expressar.

O conto "Bestiario", que dá nome ao livro, narra a presença de um tigre que convive com os integrantes de uma família, mas que em momento algum aparece ou é visto. A história alude aos grandes mistérios ou mesmo ameaças que perpassam os aspectos mais banais e cotidianos da condição humana, tal como propõe Freud ao conceituar que os sonhos são o espaço de convivência entre o que é familiar e o que é traumático ${ }^{4}$. Em certa medida, Cortázar atesta que o preenchimento ou não desses espaços tece uma linha tênue entre a realidade e a fantasia, entre a ordem e a desordem, e a concepção de Todorov sobre a dimensão do fantástico contribui para se pensar essas características:

O fantástico ocupa o tempo desta incerteza. Assim que se escolha uma das duas respostas, deixa-se o terreno do fantástico para entrar em um gênero vizinho: o estranho ou o maravilhoso. $O$ fantástico é a vacilação experimentada por um ser que não conhece mais que as leis naturais, frente a um acontecimento aparentemente sobrenatural ${ }^{5}$.

O tigre, figura de estranhamento na narrativa, dá a dimensão de existência e de imagem ${ }^{6}$ àquilo que perpassa a convivência, o estado de ser no mundo. Ao representar a violência, o mal latente, o medo, o enigma, a fantástica presença do animal situam-se no conto como manifestação da latência natural daquilo que aparentemente é distinto, estranho e quiçá perigoso, mas que ocupa o tempo todo o cotidiano de qualquer família, de qualquer indivíduo. Mais que caracterizar a linha tênue entre o comum e o que causa estranhamento como algo bom ou ruim, tanto a narrativa de

4 FREUD, Sigmund. “O 'estranho”. In: . História de uma neurose infantil e outros trabalhos, 1972.

5 TODOROV, Tzvetan. Introdução à literatura fantástica, 1975, p. 16

6 A imagem é um conceito analisado por Davi Arrigucci Jr. em relação à presença da poesia na obra de Cortázar, no texto "Esse mago, o poeta", presente em O escorpião encalacrado: a poética da destruição em Julio Cortázar (2003). O crítico analisa que, para Cortázar, “o poeta estabeleceria, como o primitivo, uma classificação dos elementos da realidade, com base na analogia sentimental” (ARRIGUCCI JR., 2003, p. 16). A partir dessa analogia, há uma espécie de aproximação entre os seres de forma que estes têm propriedades místicas comuns, o que dá vazão a uma operação poética de manifestação de um inconsciente coletivo, criando a partir dele uma imagem. A presença do tigre, em "Bestiario", parece funcionar dessa maneira. 
"Bestiario" quanto as manifestações dos personagens de Rayuela tendem a demonstrar que há uma impossibilidade, inerente à existência, de optar por apenas uma via do existir, desenhando esses abismos que parecem intrínsecos a qualquer labirinto a ser percorrido.

Não se escolhe, portanto, o outro, mas se é também o outro, todo o tempo, como supõe Horácio, quando afirma: "yo andaba como salido, volcado en otra figura del mundo, piloto vertiginoso en una proa negra que cortaba el agua del tiempo y la negaba" 7 . Estar revirado em outra figura do mundo, que desafia a própria concepção de tempo, ou seja, poder ser dois, ou mais, é como saber da própria dimensão de inconstância e assumir o duplo, o múltiplo, a desordem de ser, de beijar o conhecido e com isso, ao mesmo tempo, abrir os olhos para o aparentemente desconhecido, como se dele fosse possível se aproximar pelo próprio mecanismo do desejo: “...mis besos eran como ojos que empezaban a abrirse más allá de ella [La Maga]". Mais que o sentido ocupado pela falta, o conceito de desejo, aqui, é o de produção, conforme a inversão à ideia de Platão, de Hegel e de Freud suscitada por Deleuze e Guattari ${ }^{9}$. O desejo, manifestado em Cortázar pelo beijo que abre a possibilidade de ver seu próprio outro, não seria carência, mas um excesso que ameaça transbordar, criar, ou, nas palavras de Nietzsche, uma "vontade de potência"10. O real, afirmariam Deleuze e Guattari, “decorre disso, é o resultado das sínteses passivas do desejo como autoprodução do inconsciente" ${ }^{\prime 11}$. Assim é capaz de se ver Horácio:

Veo lo que no soy. Por ejemplo (esto lo armo de vuelta, pero sale de ahî): hay enormes zonas a las que no he llegado nunca, y lo que no se ha conocido es lo que se es. Ansiedad por echar a correr, entrar en una casa, en esa tienda, saltar a un tren, devorar todo Jouhandeau, saber alemán, conocer Aurangabad... Ejemplos localizados y lamentables pero que pueden dar una idea. (¿una idea?) ${ }^{12}$.

A fala de Horácio suscita perguntas que levam a pensar se o que deseja ser, fazer, saber dá apenas uma ideia do que é ou atesta, inevitavelmente, aquilo que propriamente também se manifesta no ato de ser. O que está presente no inconsciente - que se acessa

7 CORTÁZAR, Julio. Rayuela, 1995, p. 11.

8 Ibidem, p. 11

9 DELEUZE, Gilles; GUATTARI, Félix. O anti-Édipo: capitalismo e esquizofrenia. São Paulo: Editora 34, 2010.

10 NIETZSCHE, Friedrich. The will to power, 1968.

11 DELEUZE, Gilles; GUATTARI, Félix. O anti-Édipo: capitalismo e esquizofrenia, 2010, p. 43.

12 CORTÁZAR, Julio. Rayuela, 1995, p. 234. 
por meio do próprio desejo assumido, ou mesmo reprimido - também é o próprio ser? São questões que estão longe de se resolver na obra do argentino e que demonstram o labirinto como um espaço propício para as manifestações das impermanências, para a fuga à lógica e à razão, e para a formatação - a priori inapreensível - de um ser que não existe naturalmente para acabar em si.

\section{Outra Maga, ainda um labirinto}

Assim como as perguntas suscitadas pela narrativa de Cortázar sugerem respostas pertinentes à escolha pela via do existir, na qual a convivência com o outro não é uma opção, mas uma fatalidade, em Bolaño, o mistério ou mesmo o mal também convivem com o cotidiano daquele que empreende sua busca. Isso pode ser visto na obra Amuleto, na história de Auxilio Lacouture, inspirada na experiência real da uruguaia Alcira Scaffo, que ficou presa no banheiro da Universidad Nacional Autónoma de México, em 1968, quando o exército invadiu o recinto ao mesmo tempo em que se perpetrava o histórico massacre de Tlatelolco. A narrativa é o desenvolvimento de um fragmento de Los Detectives Salvages, que foi expandida em Amuleto, de 1999. A estratégia também é comparável à Rayuela, de Cortázar, na qual a possibilidade de leitura desordenada e mesmo separada do todo se manifesta ${ }^{13}$. A narradora - Auxilio Lacouture - inicia o romance afirmando que:

\footnotetext{
Ésta será una historia de terror. Será una historia policíaca, un relato de serie negra y de terror. Pero no lo parecerá. No lo parecerá porque soy yo la que lo cuenta. Soy yo la que habla y por eso no lo parecerá. Pero en el fondo es la historia de un crimen atroz ${ }^{14}$.
}

A possibilidade de compreender como a pretensa "história de horror" irá se desenvolver, entre sonhos, devaneios e loucura, é logo desacreditada pela própria narradora. Esta afirma que o horror não parecerá verdade porque a história é contada por ela, a mulher que ficou presa no banheiro enquanto os militares tomavam a universidade. No tempo presente da narrativa, essa mulher transforma em forma e em tema seu próprio acesso a um inconsciente coletivo de dor e repressão, cuja manifestação poética se dá nas texturas da própria insanidade.

13 O capítulo 68 de Rayuela, quando a Maga escreve a seu filho, o bebê Rocamadour - que só é destinatário de sua mãe porque ainda não sabe ler -, poderia muito bem ser a abertura de uma narrativa maior, expandida, tal qual a de Auxilio, cujo trauma é movedor do romance de Bolaño.

14 BOLAÑO, Roberto. Amuleto, 2017, p. 09. 
A narradora de Amuleto é responsável pela construção de um caminho também labiríntico ${ }^{15}$ ao tecer uma rememoração fragmentada e dispersa de seu passado, assim como dos 13 dias em que esteve presa num dos banheiros da UNAM. Também os acontecimentos posteriores à invasão formataram sua figura enquanto a mulher mítica que resistiu sozinha dentro do campus, uma vez que a experiência traumática da personagem surge em diversas das esquinas e transições que permitem a lapidação da história. A primeira aparição do ocorrido no banheiro da universidade se dá na página 22, quando Auxilio afirma que "estaba en el baño, en los lavabos de una de las plantas de la Facultad, la cuarta, creo, no puedo precisarlo" e não são raras essas menções, como em "Otra vez estaba en el lavabo de mujeres de la cuarta planta de la Facultad de Filosofía y Letras y era septiembre de 1968 y yo pensaba en las aventuras y en Remedios Varo"16.

No entanto, com o decorrer das digressões e das possibilidades de recordar o passado, a narração do que supostamente já aconteceu ocupa o presente, ao final no livro, o que demonstra a permanência da experiência do trauma na experiência cotidiana da narradora: "Estoy en el lavabo de mujeres de la Facultad y puedo ver el futuro" 17 . Trazer o passado para o presente, como se as fronteiras temporais em alguma medida se desfizessem, transporta o trauma de Auxilio para o seu cotidiano, ao mesmo tempo em que leva a narradora para o acontecimento em si. Diante de imprecisões que manifestam a legitimidade do existir dentro de um labirinto propriamente cortazariano, na permanência do ser aqui e lá, é que a linguagem propicia mais uma vez a compreensão de que a via múltipla é justamente a maneira pela qual é possível dizer o que de fato ocorreu.

Enquanto narra, Auxilio se perde dentro de sua própria temporalidade, e "isso" ou "aquilo", além de um sem número de "talvez", constroem a falta de linearidade de sua experiência: "Yo llegué a México Distrito Federal en el año 1967 o tal vez en el año

15 A construção labiríntica da Cidade do México, assim como ocorre com a Paris, de Rayuela, também é verbalmente expressada pela narradora, quando empreende uma busca à casa de Elena, uma jovem recém-formada em Filosofia, que conheceu por acaso no campus universitário: "Una tarde decidí ir a su casa pero me perdí. ¡Era la primera vez que me pasaba una cosa semejante! ¡Desde septiembre de 1968 yo no me había perdido ni una sola vez en el laberinto del DF! Antes sí, antes solía perderme, no muy a menudo, pero solía perderme. Después ya no. Y ahora estaba allí, buscando su casa y no la encontraba y entonces me dije aquí pasa algo raro, Auxilio, nena, abre los ojos y fíjate en los detalles, no sea que se te pase por alto lo más importante de esta historia. Y eso fue lo que hice. Abrí los ojos y vagué por Coyoacán hasta las once y media de la noche, cada vez más perdida, cada vez más ciega, como si la pobre Elena se hubiera muerto o nunca hubiera existido" (Ibidem, p. 37 e 38).

16 Ibidem, p. 75.

17 Ibidem, p. 110. 
1965 o 1962." 18 . Sobre esse aspecto narrativo em Amuleto, Jaime Concha afirma que "La conjunción disyuntiva que, como su nombre lo indica, es conyuntiva y disyuntiva a la vez, crea una cadena de alternativas, que son a la vez alternancias, oscilaciones entre dos o más posibilidades, unificando, bifurcando, a menudo trifurcando las líneas narrativas" $"$.

Mais do que fragmentar e, nas palavras do crítico, trifurcar as possibilidades narrativas, pode-se afirmar que tanto o passado - impreciso e ao mesmo tempo essencial para a materialidade do ocorrido - quanto o futuro, visto pela narradora quando se transporta novamente para o banheiro, tornam-se espaços de reminiscência, de lembrança, ou mesmo de criação, de desejo ${ }^{20}$. É o espaço de convivência constante com o mal, representativo do trauma, que permite a criação narrativa. Assim, quando formulada no presente e analisada sob o ponto de vista de sua necessidade para o vislumbre do futuro, a lembrança traumática é, portanto, ponto central na produção do que virá. A ruptura da linearidade e da temporalidade demonstram-se, nessa medida, como desencantos históricos diante da materialidade e da violência endêmica no México e em toda a América Latina. Mais do que vias que se bifurcam, tempos que se confundem, personalidades que se dissolvem e se fundem em estranhamentos, a loucura - uma das poucas características aparentemente capaz de concentrar todos esses devaneios - torna-se a estética da obra e também o único compromisso possível em relação ao estado de coisas ao redor.

Para Cecilia López Badano, em um artigo em que compara Bolaño e Cortázar, Amuleto apresenta:

en variados elementos lo que Sarlo, caracterizando el rasgo principal de la escritura cortazariana, denominara "el pasaje entre espacios que la percepción normalizada mantiene escindidos" (Suma 265); esos espacios, al consumar en su juntura una representación alterada de lo cotidiano, logran desnaturalizar su aprehensión intelectual ${ }^{21}$.

Para López Badano, essa instabilidade pode ser vista no momento em que Auxilio observa com detenção um vaso de flores, que de súbito se transforma para a

18 Ibidem, p. 10.

19 CONCHA, Jaime. "Geometrias de Bolaño. Observações sobre Amuleto”. In: Leer a contraluz: Estudios de la narrativa chilena. De Blest Gana a Varas y Bolaño, 2012, p. 352.

20 DELEUZE, Gilles; GUATTARI, Félix. O anti-Édipo: capitalismo e esquizofrenia, 2010.

21 LÓPEZ BADANO, Cecilia. "Construcciones estéticas intertextuales: ecos postmodernos de Cortázar en tres 'generaciones' literarias latinoamericanas (Bolaño, Bellatín, Busqued), noviembre de 2014, p. 03. 
ela em uma "boca del infierno", porque "allí está todo lo que la gente ha perdido, todo lo que causa dolor y lo que más vale olvidar" 22 . No entanto, longe do esquecimento, o trauma convive com a lembrança constante na narrativa, e o que é cotidiano transformase assim em um abismo para onde caminham também todos os que entram nesse labirinto. Em Cortázar, o abismo é parte do caminho, com o qual é possível se deparar em diversos momentos, fazer o contorno e permanecer na busca (o tigre permanece dentro da casa em "Bestiario"; o desejo de ser outro do narrador convive com o beijo na boca conhecida em Rayuela). Já em Bolaño, o abismo parece ser a única saída, a única maneira de superar ou ao menos de fugir de um mal plenamente instaurado e implacavelmente cotidiano. Quando se depara com o vaso de flores de Pedro Garfias e nele vê uma "boca del infierno", Auxilio em certa medida demonstra que é no cotidiano dos poetas, dos jovens poetas da América Latina, em suas casas, em seus "floreros", que é possível ver onde se abre o abismo para onde todos se destinam:

Y entonces pensé: ¿Pedrito Garfias sabe lo que se esconde en el interior de su florero? ¿Saben los poetas lo que se agazapa en la boca sin fondo de sus floreros? ¿Y si lo saben por qué no los destrozan, por qué no asumen ellos mismos esta responsabilidad? ${ }^{23}$

A narradora se pergunta por que os poetas não assumem a responsabilidade de quebrar esses vasos que agora, para ela, se apresentam como caminhos em direção ao fim, ao desconcerto histórico. Dessa forma, tal como Marcel Schwob, em "A Cruzada das Crianças", essa fundamentação distópica empreendida pelo autor chileno em Amuleto e manifestada em uma loucura paradoxal expressa lucidamente parte do destino da América Latina. Esse destino é atestado ao final, quando a narradora descreve a cena desses jovens, os mesmos que não assumiram a responsabilidade de perceber e de enfrentar o mal cotidiano que os assombrava. São esses os jovens dos quais ela se intitulou mãe, (a mãe de todos os poetas), que não tinham outro destino senão caminhar em direção a um abismo político cavado pelo terror e a repressão que se espalhou por diversos países latino-americanos, e por um desencanto histórico que o sucedeu:

Cuando llegué junto al árbol los pájaros habían volado. Entonces vi que por el otro extremo del valle, por el oeste, se abría un abismo sin fondo. ¿Me estoy volviendo loca?, pensé. [...] Luego miré el abismo. Se me

22 BOLAÑO, Roberto. Amuleto, 2017, p. 14.

23 Ibidem, p. 14. 
encogió el corazón. Ese abismo marcaba el final del valle. [...] Y supe que la sombra que se deslizaba por el gran prado era una multitud de jóvenes, una inacabable legión de jóvenes que se dirigía a alguna parte. Los vi. Estaba demasiado lejos para distinguir sus rostros. Pero los vi. [...] Supe también que pese a caminar juntos no constituían lo que comúnmente se llama una masa: sus destinos no estaban imbricados en una idea común. Los unían sólo su generosidad y su valentía. Conjeturé (con las palmas de las manos apoyadas en mis mejillas) que también ellos habían vagado por las montañas nevadas y que allí se habían ido encontrando y caminando juntos hasta formar un ejército que ahora se desplazaba por el prado. Caminaban hacia el abismo. Creo que eso lo supe desde que los vi. Sombra o masa de niños, caminaban indefectiblemente hacia el abismo ${ }^{24}$.

“Dizer o acontecimento, é possível?”. A pergunta de Jacques Derrida, feita durante um seminário em 1997, no Centro Canadense de Arquitetura, serve para pensar esse caminho percorrido por Auxilio Lacouture em Amuleto. Para o autor, em certa medida, o dizer é também o mecanismo produtor do próprio acontecimento em si. A promessa e o sacrifício, por exemplo, aparecem para Derrida como ocorrências que se dão com o próprio ato de dizê-las. Prometer, em si, é um acontecimento. Quando Auxilio, no início de Amuleto, afirma que o que contará será uma história de horror, embora não pareça porque é ela quem conta, o simples ato da enunciação, de ali em diante, é ao mesmo tempo criador tanto do próprio acontecimento quanto da loucura que o fará parecer inverossímil. Essa fusão entre as três instâncias - o ato de dizer, quem diz e o acontecimento em si - é o que Derrida denominaria um performativo. No caso de Auxilio, há tanto uma espécie de promessa do que virá, quanto uma instabilidade que linguisticamente se apresenta inerente a essa possibilidade de futuro. A história de horror, de massacre, de violência, materializada na clausura de uma mulher durante 13 dias no banheiro da universidade não parecerá uma história de horror, de massacre nem de violência, pois a própria loucura da mulher que narra, produto possivelmente desse trauma, tornará questionável a verdade da memória retomada. Não à toa, Derrida ressalta o fato de que,

ainda que o performativo diga e produza o acontecimento do qual ele fala, ele o neutraliza também, na medida em que ele guarda seu domínio em um "eu posso" (I can, I may), "eu estou habilitado" etc. Um acontecimento puro, e digno desse nome, desconcerta o performativo tanto quanto o constativo. Será preciso um dia tirar daí todas suas consequências ${ }^{25}$.

24 Ibidem, p. 123-125.

25 DERRIDA, Jacques. "Uma certa possibilidade impossível de dizer o acontecimento/Une certaine possibilité impossible de dire l'événement.", 2012, p. 249. 
Isso significa que se habilitar a dizer o horror é tanto um ato performativo - e uma produção do acontecimento em si - quanto uma desconstrução do próprio ato e de sua própria existência enquanto fato. Daí que, ao narrar o trauma, Auxilio permite sua construção imagética e, ao mesmo tempo, sua destruição que também é por ela prevista logo no início do livro. Mais uma vez, não é à toa que ela não se exima do fim quando descreve a impossibilidade de fuga do abismo para o qual todos os jovens se destinam. Como mãe de todos os poetas, e mesmo mãe de toda a obra, mais que uma busca que invariavelmente terminará no abismo, pela leitura do que diz Derrida, ela seria a responsável pela própria produção de tal destino.

No entanto, esse duplo mecanismo que constrói para destruir também funcionaria de outra maneira, destruindo para construir. $\mathrm{E}$ é nesse momento que a convivência com o que se é, de louco e de são, de começo e de fim, de passado e de futuro, compõe o que Jeanne Marie Gagnebin chama de imagem do labirinto, "metáfora ao mesmo tempo das relações temporais entre presente, passado e futuro e das relações privilegiadas que o sujeito entretém consigo mesmo"26. Então, para narrar o trauma, mais que trazer um tema de dor e violência, Bolaño escolhe a forma labiríntica, na qual essas possibilidades convivem o tempo todo com a latência da loucura, com o estranhamento e com a própria materialização do mal.

O mesmo se dá em Cortázar, no qual a crítica à razão é a convivência com o outro, o duplo, aquilo que é inerente para que se permaneça sendo, um caminho que manifesta o estranhamento e também o propósito de simplesmente caminhar:

Podía ocurrir que la traición se consumara en una perfecta soledad, sin testigos ni cómplices: mano a mano, creyéndose más allá de los compromisos personales y los dramas de los sentidos, más allá de la tortura ética de saberse ligado a una raza o por lo menos a un pueblo y una lengua. En la más completa libertad aparente, sin tener que rendir cuentas a nadie, abandonar la partida, salir de la encrucijada y meterse por cualquiera de los caminos de la circunstancia, proclamándolo el necesario o el único. La Maga era uno de esos caminos, la literatura era otro (quemar inmediatamente el cuaderno aunque Gekrepten se re-tor-cie-ra las manos), la fiaca era otro, y la meditación al soberano cuete era otro. Parado delante de una pizzería de Corrientes al mil trescientos, Oliveira se hacía las grandes preguntas: «Entonces, chay que quedarse como el cubo de la rueda en mitad de la encrucijada? ¿De qué sirve saber o creer saber que cada camino es falso si no lo caminamos con un propósito que ya no sea el camino mismo? No somos Buda, che, aquí no hay árboles donde sentarse en la postura del loto ${ }^{27}$.

26 GAGNEBIN, Jeanne Marie. História e narração em Walter Benjamin, 1994, p. 86.

27 CORTÁZAR, Julio. Rayuela, 1995, p. 167. 
Se a crítica de Cortázar ao peronismo em certa medida se aproxima da crítica de Bolaño às ditaduras, não se pode deixar de dizer que o chileno vai ao extremo da convivência com o mal. Ele o atualiza dentro do cotidiano, retirando as distâncias e, mesmo em meio à loucura, ao sonho, ao devaneio, instaurando como vórtice do que narra o mal como fundamento e como destino do que se narra (só se conta o horror porque ele já ocorreu e enquanto ele é contado seu destino é que novamente ocorra). Não é apenas a convivência com o outro que está em questão, mas a transformação do próprio ser - que não quebra seus vasos de flores, aqueles que levam ao inferno - em um mal familiar, levado ao abismo cantando o desencanto histórico que virá. Entretanto, não se pode dizer que isso, em Bolaño, seja apenas seu, porque é no labirinto, em si, que toda essa possibilidade ocorre. Seja para o abismo ou por entre abismos, ainda é um labirinto, cujo acontecimento, em si, se apelássemos a Derrida, seria por si só um gênero discursivo. É possível dizer o acontecimento? Cortázar e Bolaño talvez não respondessem que sim nem que não, mas se perguntariam: de que forma quer que o teçamos?

\section{Referências}

ARRIGUCCI Jr., Davi. O Escorpião Encalacrado. A poética da destruição em Julio Cortázar. São Paulo: Companhia das Letras, 1995.

BOLAÑO, Roberto. Amuleto. Barcelona: Vintage Español, 2017.

BOLAÑO, Roberto. Los Detectives Salvages. Barcelona: Anagrama, 2006.

CONCHA, Jaime. “Geometrias de Bolaño. Observações sobre Amuleto”. In: Leer a contraluz. Estudios de la narrativa chilena. De Blest Gana a Varas y Bolaño. Santiago de Chile: Ediciones Universidad Alberto Hurtado, 2012.

CORTÁZAR, Julio. Bestiario. Editora Nova Fronteira, 1986.

CORTÁZAR, Julio. "Para uma poética”. In: CORTÁZAR, Julio. Valise de Cronópio. São Paulo: Perspectiva, 1993.

CORTÁZAR, Julio. Rayuela. Buenos Aires: Editorial Sudamericana, 1995.

DELEUZE, Gilles; GUATTARI, Félix. O anti-Édipo: capitalismo e esquizofrenia. São Paulo: Editora 34, 2010. 
DERRIDA, Jacques. "Uma certa possibilidade impossível de dizer o acontecimento/ Une certaine possibilité impossible de dire l'événement." Trad. EYBEN, P. In: Revista Cerrados, 2012. Disponível em: http://periodicos.unb.br/ojs248/index.php/ cerrados/article/view/8242/6240. Acesso em: 10 mar. 2020.

ECO, Umberto. "Prólogo". In: SANTARCANGELI, P. In: El libro de los laberintos: historia de un mito y de un símbolo. Madrid: Siruela, 1997.

FREUD, Sigmund. “O 'estranho”'. In: FREUD, Sigmund. História de uma neurose infantil e outros trabalhos. Rio de Janeiro: Imago, 1972.

GAGNEBIN, Jeanne Marie. História e narração em Walter Benjamin. São Paulo: Perspectiva, 1994.

LÓPEZ BADANO, Cecilia. “Construcciones estéticas intertextuales: ecos postmodernos de Cortázar en tres 'generaciones' literarias latinoamericanas (Bolaño, Bellatín, Busqued). (Universidad Autónoma de Querétaro)". Rev. Chasqui, noviembre de 2014.

NIETZSCHE, Friedrich. The will to power. Tradução de Walter Kaufmann e R. Hollingdale. Nova York: Vintage Books, 1968.

TODOROV, Tzvetan. Introdução à literatura fantástica. Tradução de Maria Clara Correa Castello. São Paulo: Perspectiva, 1975.

VIÑAS, David. De Sarmiento a Cortázar. Buenos Aires: Ediciones Siglo Veinte, 1972.

YURKIEVICH, Saúl. Julio Cortázar: mundos y modos. Buenos Aires: Edhasa, 2004.

Submissão: 20/05/2020

Aceite: $30 / 08 / 2020$

https://doi.org/10.5007/2176-8552.2020.e72581

Esta obra foi licenciada com uma Licença Creative Commons Atribuição-NãoComercial 4.0 